This item was submitted to Loughborough's Research Repository by the author.

Items in Figshare are protected by copyright, with all rights reserved, unless otherwise indicated.

\title{
Measuring job quality: a study with bus drivers
}

PLEASE CITE THE PUBLISHED VERSION

http://dx.doi.org/10.1016/j.apergo.2014.05.015

\section{PUBLISHER}

C) Elsevier Ltd and The Ergonomics Society

\section{VERSION}

AM (Accepted Manuscript)

\section{PUBLISHER STATEMENT}

This work is made available according to the conditions of the Creative Commons Attribution-NonCommercialNoDerivatives 4.0 International (CC BY-NC-ND 4.0) licence. Full details of this licence are available at: https://creativecommons.org/licenses/by-nc-nd/4.0/

\section{LICENCE}

CC BY-NC-ND 4.0

\section{REPOSITORY RECORD}

Jones, Wendy, Roger Haslam, and Cheryl Haslam. 2019. "Measuring Job Quality: A Study with Bus Drivers". figshare. https://hdl.handle.net/2134/17689. 


\section{Measuring job quality: a study with bus drivers}

Wendy Jones ${ }^{\mathrm{a}}$, Roger Haslam ${ }^{\mathrm{a}}$, Cheryl Haslam ${ }^{\mathrm{b}}$

aLoughborough Design School, Loughborough University, Loughborough LE11 3TU, United Kingdom

bSchool of Sport, Exercise and Health Sciences, Loughborough University, Loughborough LE11 3TU, United Kingdom

w.jones2@lboro.ac.uk (corresponding author) 01509228485

r.a.haslam@lboro.ac.uk

c.o.haslam@lboro.ac.uk

\section{Abstract}

There is growing interest in the contribution which job design can make to worker health; also a desire to better understand the multidimensional notion of 'job quality' and to develop approaches to measuring this. This paper reviews concepts of 'job quality' and 'good jobs' and examines these issues in the work of bus drivers, an occupational group commonly reported as having poor health and poor working conditions. The DGB-Index, a tool used recently in Germany for measuring job quality, was translated and administered to a sample of UK bus drivers $(n=381)$ and found that job quality was significantly lower than that for a group of non-drivers in the same organisation; and better than that for a sample of German bus drivers. We conclude that the DGB-Index is an effective tool for measuring job quality and providing feedback to employers, and could be used to compare job quality between organisations or internationally.

\section{Keywords}

job quality; bus drivers; DGB-Index 


\section{Introduction}

There is increasing interest in the relationship between job quality and health worldwide. This includes the traditional focus on the potential impact of poor quality jobs on health, recognising that over 2 million people world-wide die annually as a result of an accident or illness associated with their work (World Health Organization, 2010). However, there is also a growing interest in the role of good quality work in maintaining and improving individual health and wellbeing, reflecting the positive contribution that work can make to physical, mental and emotional health (Smith et al., 2011; Straker and Mathiassen, 2009; Warr, 2007; Ward et al., 2008).

The European Union has a particular interest in being able to assess job quality in different countries and in making comparisons between different groups of workers (Muñoz de Bustillo Llorente et al, 2009). By enabling better understanding and learning from areas of good practice, such data could help to raise standards in particular industries towards the level of the highest performing countries. However, this presupposes that there is a universal model of a 'good' job. In reality, the job features which are highly regarded in one country may be considered much less valuable in others - for example, for Japanese employees usefulness to society is the most important feature of a good job; whilst within America and Europe, job security and interesting work are the most critical (Muñoz de Bustillo Llorente et al, 2009). A key difficulty when measuring job quality then, is that there is 'no international agreement as to what job quality is and how it might be measured' (Muñoz de Bustillo et al., 2011). In addition to international and cultural differences in perceptions of what contributes to good quality work (Wallace et al., 2007), there are 
also differences between individuals, influenced by factors such as age, gender and various personality attributes (see Warr (2007) for a review), as well as personal and socioeconomic circumstances (Cooke et al., 2013; Loughlin and Murray, 2013). Further more, there is uncertainty regarding the exact contributions of particular characteristics- for example whether each might contribute positively to job quality or is important only to prevent it being poor (Warr, 2007; Smith et al, 2011).

Despite the lack of an agreed, comprehensive model of job quality, there is a strong evidence base regarding the aspects which it might include, and the individual factors which are known to influence health; albeit with some uncertainty regarding the exact contributions of particular characteristics - for example whether each contributes positively to job quality or is important only to prevent it being poor (Warr, 2007; Smith et al., 2011). For example, Coats and Lekhi (2008) have suggested that a good job should encompass:

- employment security

- whether work is characterised by monotony and repetition

- whether employees have autonomy, control and task discretion

- balance between efforts and rewards

- whether workplace procedures are seen to be fair

- the strength of workplace relationships -or social capital

Similar elements form the basis of well-known models of Effort-Reward Imbalance (Siegrist, 1996) and Job Strain (Karasek, 1979). However in addition to these psychosocial aspects, a comprehensive measure of job quality must also consider physical factors which can impact on health such as manual handling, exposure to 
hazardous substances, working hours, and environmental conditions. Ergonomics as a discipline is familiar with such a broad approach (Niu, 2010); and also with the importance of demonstrating that improved job quality can be a good business decision (Hendrick, 2008), so that its assessment is important for employers and governments as well as for employees.

The DGB-Good Work Index (DGB-Index) is a job quality measurement tool developed for the German Trade Union Confederation (Deutscher Gewerkschaftsbund, DGB) which has been used annually in Germany since 2007, surveying approximately 6000 workers each time. A low score on the DGB-Index is associated with being more likely to change one's employer, and less likely to feel that one's health will permit working up to retirement age (Mussman, 2009). Occupational roles which score most highly on the index in Germany include administration, engineering and child care: whilst agriculture, construction and transport score poorly. These conclusions accord with the findings drawn for Europe as a whole using data from the European Working Conditions Survey (EWCS) (Parent-Thirion et al, 2007).

The current study will extend the research on job quality measurement by translating the DGB-Index into English and testing it in the UK. If language and cultural differences can be resolved, this will extend the utility of the tool, making it available for those seeking to measure and subsequently improve job quality in countries other than Germany. There could also be scope for comparisons between different countries as discussed above. 


\section{The DGB Index}

The DGB Index is made up of three sub-indices: Resources, Burdens, and

Income/security. These in turn comprise 15 dimensions, assessed by 31 questions

on relevant factors, summarised in Table 1.

Table 1. Structure of the DGB-Index tool, showing how the individual factors combine to form dimensions and partial indices

(adapted from Mussman, 2009)

\begin{tabular}{|c|c|c|}
\hline Partial index & Dimension & Factors \\
\hline \multirow{19}{*}{ Resources } & \multirow{2}{*}{$\begin{array}{l}\text { Training and } \\
\text { learning }\end{array}$} & Training opportunities \\
\hline & & Skills development opportunities \\
\hline & Creativity & Opportunities to use own ideas \\
\hline & Promotion & Promotion prospects \\
\hline & \multirow{3}{*}{ Control over work } & Opportunities to plan work \\
\hline & & Influence over amount of work \\
\hline & & Influence over how work time is organised \\
\hline & \multirow{2}{*}{$\begin{array}{l}\text { Information, } \\
\text { communication }\end{array}$} & Access to necessary information \\
\hline & & Conflicting or contradictory demands \\
\hline & \multirow{3}{*}{ Manager } & Work planned well by supervisor/line manager \\
\hline & & Appreciation from supervisor/line manager \\
\hline & & Personal development valued by manager \\
\hline & \multirow{2}{*}{$\begin{array}{l}\text { Senior manager, } \\
\text { culture }\end{array}$} & Cooperation encouraged \\
\hline & & Competent management \\
\hline & Relationships, & Support from colleagues \\
\hline & Meaningful & Work useful for society \\
\hline & \multirow{3}{*}{ Hours } & Control over how much overtime worked \\
\hline & & Working hours reliable and predictable \\
\hline & & $\begin{array}{l}\text { Personal needs considered when working hours are } \\
\text { planned }\end{array}$ \\
\hline \multirow{8}{*}{ Burdens } & \multirow{3}{*}{$\begin{array}{l}\text { Pressure, } \\
\text { intensity }\end{array}$} & Unwanted interruptions \\
\hline & & Work with high time pressure \\
\hline & & Need to compromise work quality \\
\hline & \multirow{2}{*}{$\begin{array}{l}\text { Emotional } \\
\text { demands }\end{array}$} & Need to hide feelings \\
\hline & & Respect from others \\
\hline & \multirow{3}{*}{$\begin{array}{l}\text { Physical } \\
\text { demands }\end{array}$} & Physically hard work \\
\hline & & Working under strain, poor postures \\
\hline & & Loud noise exposure \\
\hline \multirow{4}{*}{$\begin{array}{l}\text { Income and } \\
\text { security }\end{array}$} & Job security & Worry about job/work future \\
\hline & \multirow{3}{*}{ Income } & Fair pay \\
\hline & & Enough pay \\
\hline & & Enough pension \\
\hline
\end{tabular}


Each question is in two parts - the employee is asked firstly whether they consider that particular factors are present in their workplace, and then whether the absence of good features (or the presence of bad features) bothers them. This two part question format is a significant strength of the index, as it takes into account the way in which individual preferences influence personal experiences of work.

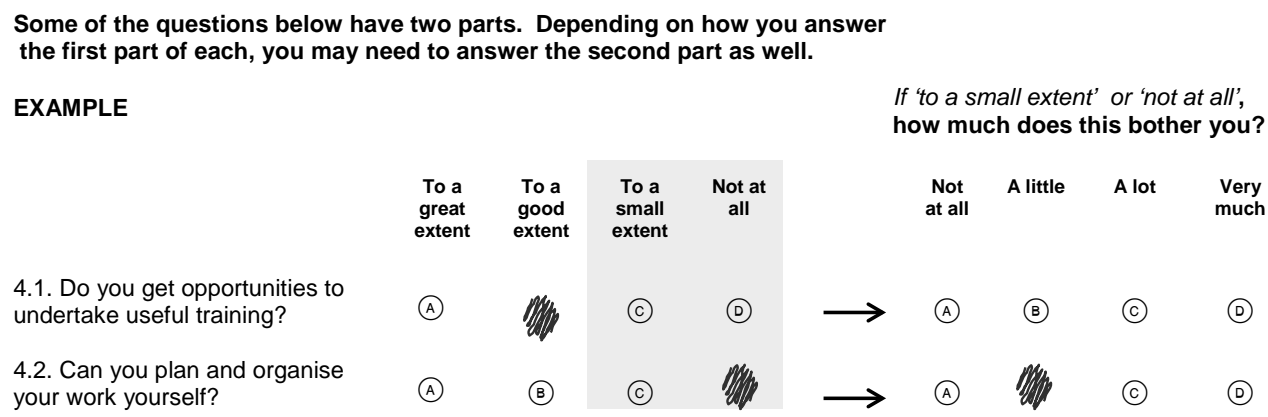

Figure 1 Sample questions from the DGB-Index tool, showing the two part structure of the questions

A structured scoring algorithm combines the responses to allocate a final score out of 100 for each sub-index and for the overall DGB-Index, allowing jobs to be classified as being good, medium or poor. Good work is that which scores 80 points or higher, with 50 being the cut off between poor and medium quality work. German data from 2010 (DGB-Index010) identified 15\% of respondents as being in jobs which were good, $52 \%$ were in medium quality jobs and $33 \%$ were in jobs which were poor.

The DGB-Index is not without its critics. Prümper and Richenhagen (2009) have suggested that the scoring system permits good work to be mis-classified as being only medium quality: and that the tool places too much weight on income and security. These claims have been refuted by Fuchs (2010). A further concern raised 
by Prümper and Richenhagen (2009) is the lack of published validity and reliability data. This deficit has been addressed in a recent independent review (Schütte, 2011), based on the data of 16,268 DGB-Index respondents gathered over a four year period.

\section{Methodology}

\section{Translation and development of the DGB-Index tool}

As the DGB-Index tool had not previously been used outside of Germany, it needed to be translated into English for the current study. The following steps were taken to achieve this:

- translation of questions using three separate online translation tools (World Lingo, Freetranslation, and Babel) and reference to an existing DGB-Index conference paper (Mussman, 2009) to produce a first draft

- revision of the draft to improve the clarity and structure of questions.

- review of the draft by two native English speakers who were fluent in German; and by an academic member of the advisory board of the DGB-Index, who was a native German speaker and fluent in English. The final version took into account all comments, ensuring that each question was clear and coherent in English whilst still being as close in meaning to the German version as possible

Once the main DGB-Index questionnaire had been translated, four additional questions were added, each with a five point response scale: 
Do you consider your job to be a good job?

Do you consider your job to be generally good for your health?

How is your health, in general?

Thinking about your health and the job you do at the moment, will you still be able to manage it when you are 65?

Subjective single item measures such as these are often used to assess job satisfaction or wellbeing; such questions have limited use as a measure of job quality in themselves due to the influence of employee expectations on their responses, but they can be used in combination with more specific measures to guide understanding about the judgements individuals make regarding job quality (Kalleberg and Vaisey, 2005). In the current study these were also chosen to support assessment of the validity of the index. Questions to collect personal data (age, length of service, marital status etc.) were also included.

The tool was pilot tested with seven postgraduate students at a UK University (two of whom spoke English as a second language). The students had no difficulty understanding the questions and all successfully completed the questionnaire. The results were analysed and scored on the DGB-Index algorithm; the scores were in line with expectations given the role of a PhD student, with high scores for creativity, training and learning and relationships, and very low scores for income and job security.

A further pilot test was carried out with a cohort of cleaners, employed within a UK university. Only $26 \%$ of 73 returned questionnaires were correctly completed, with 
many respondents apparently struggling with the two-part structure of the questions. As a result of this, revisions were made which included the addition of the worked example question shown in Figure 1. The labels on the four point response scales were also modified to improve clarity, Figure 1 shows the final version. This had been an area of particular challenge during the initial translation, as direct interpretation of the German scales gave responses such as 'in very high measure', and it was difficult to find meaningful alternatives.

\section{Study population}

Bus drivers were chosen as a study group as they are a population who are commonly reported to have poor health, and poor working conditions, and could thus benefit from improved job quality. The European Working Conditions Survey (EWCS) has identified land transport as one of the worst employment sectors in Europe with long, non-standard working hours; low job control; and low skill use (Jettinghoff and Houtman, 2009). Bus drivers have been reported as having a high risk of heart disease (Morris et al., 1953), as well as back pain (Okunribido et al., 2007) gastrointestinal disorders, musculoskeletal problems and poor mental health (Tse et al., 2006). They report stress and fatigue which they associate with the demands of passengers, traffic, and timetables (Biggs et al., 2009; Tse et al., 2007; Salmon et al., 2011) and suffer from a high incidence of obesity (Chung and Wong, 2011; French et al., 2010). Within the UK, bus drivers can be found at the bottom of tables on job satisfaction (Rose, 2003), and similarly poor conditions and health issues have also been identified in many countries including America (French et al., 2010), Norway (Glasø et al., 2011) and Taiwan (Chung and Wong, 2011). 
A large, urban bus company in the UK participated in the study. The company was one acknowledged in the industry as being a good employer, paying relatively high wages to its 800 drivers, and recognised for its commitment to staff training and development. Table 2 shows the characteristics of the study population.

Table 2. Employee characteristics for the bus driver population of the company studied

\begin{tabular}{|l|l|}
\hline Age & Average 46.3 years (sd=10.29, range 20-65) \\
\hline Gender & $93 \%$ male, $7 \%$ female \\
\hline Ethnicity & $\begin{array}{l}86.6 \% \text { white British,4.5\% Caribbean, } 2.2 \% \text { white } \\
\text { other, } 2.2 \% \text { Pakistani, } 1.5 \% \text { Indian, } 1.5 \% \text { mixed race }\end{array}$ \\
\hline Length of service & $\begin{array}{l}\text { Average } 10 \text { years, }(\mathrm{sd}=9.80, \text { range } 3 \text { months-46 } \\
\text { years) }\end{array}$ \\
\hline Contract details & $\begin{array}{l}97.2 \% \text { full time (typically } 39 \text { hours each week over } 5 \\
\text { days, with an optional } 6^{\text {th }} \text { day); } \\
2.8 \% \text { part time }\end{array}$ \\
\hline
\end{tabular}

\section{Data collection and analysis}

Completion of the questionnaire was incorporated into a mandatory training session which was already scheduled by the bus company prior to the commencement of the study. This was attended by 413 bus drivers during the study period, which was half of all drivers employed across the organisation. Nine drivers (1\%) did not attend for training due to absence on long term sickness, the remaining $49 \%$ had previously attended the same training session.

The allocation of the drivers to training sessions on a particular date was based on operational factors such as shift patterns and availability. Comparison between those involved in the study and the rest of the population shows that the two were similar apart from small differences in age and length of service: weighting for these differences did not significantly affect the results. 
All the drivers who attended the training course completed the questionnaire i.e. a $100 \%$ response rate. Completed forms were then scanned: responses were converted into scores out of 100 for each question and each individual, and were combined to produce DGB-Index scores for the population. Questionnaires were removed from the dataset if they were insufficiently or incorrectly completed, such that calculation of a valid score for an individual was not possible. Generally those with more than 7 errors or missing questions were removed (further details available from the author on request). Table 3 shows the overall response rates contributing to the final sample.

Table 3 Response rates for questionnaires

\begin{tabular}{|l|l|l|}
\hline & Drivers & Non-drivers \\
\hline Population (N) & 413 & 44 \\
\hline Returned questionnaires & $413(100 \%)$ & $44(100 \%)$ \\
\hline Incomplete questionnaires & $32(8 \%)$ & $2(6 \%)$ \\
\hline Final sample (n) & $381(92 \%)$ & $42(94 \%)$ \\
\hline
\end{tabular}

A number of non-drivers also completed the questionnaire. These were managers, inspectors and supervisors who attended training as they held a Passenger Carrying Vehicle (PCV) license. These responses were analysed separately.

The DGB-Index scores were analysed using SPSS 19, and results were considered alongside the published norms for the tool. Cronbach's alpha for the overall scale was 0.889 . Scores for the partial indices were slightly lower at 0.85 (Resources) 0.787 (Burdens) and 0.654 (Income). 


\section{Results}

Overall, the job of a bus driver in this organisation scored 61.8, putting it in the category of 'medium quality work' according to the reference literature. The job of a bus driver scored significantly lower than the job of a non-driver within the organisation for the overall score and for the partial indices Resources and Burdens (Table 4).

As Table 4 also shows, the drivers in this organisation scored significantly higher than the bus drivers in the German dataset. This may reflect differences in how the DGB-Index tool measured job quality, as a result of translation and/or a different culture; or may illustrate that the job quality of bus drivers in the UK sample is genuinely better than that of their German counterparts. This will be explored further in the discussion.

Table 4. DGB-Index scores overall and by partial indices, for UK bus drivers, UK non drivers and German bus drivers (Means compared using a two tailed independent samples $t$ test)

\begin{tabular}{|c|c|c|c|c|c|c|c|c|c|}
\hline & & $\begin{array}{l}\text { DGB-I } \\
\text { overal }\end{array}$ & & Resol & & Burde & & Incom & ecurity \\
\hline & $\mathbf{n}$ & mean & SD & mean & SD & mean & SD & mean & SD \\
\hline Total for UK bus drivers & 381 & 61.76 & 15.99 & 70.01 & 13.06 & 66.11 & 21.08 & 49.15 & 24.82 \\
\hline $\begin{array}{l}\text { Total for UK non-bus } \\
\text { drivers }\end{array}$ & 42 & 69.49 & 13.96 & 80.10 & 13.69 & 73.30 & 17.04 & 55.08 & 22.09 \\
\hline $\begin{array}{l}\text { Differences between } \\
\text { drivers and non-drivers }\end{array}$ & & ** & & * & & $\star \star \star \star ~$ & & & \\
\hline $\begin{array}{l}\text { Total for German bus } \\
\text { drivers }\end{array}$ & 72 & 49.34 & 19.03 & 58.60 & 18.66 & 55.23 & 24.88 & 32.88 & 26.9 \\
\hline $\begin{array}{l}\text { Differences between UK } \\
\text { bus drivers and German } \\
\text { drivers }\end{array}$ & & * & & * & & * & & * & \\
\hline
\end{tabular}

${ }^{*} p<0.001{ }^{* *} p<0.005{ }^{* * *} p<0.05$

Figure 2 identifies how the UK bus drivers scored on individual dimensions. As with job quality overall, the majority fell into the category of 'medium'. Only the 
dimensions relating to meaningfulness of work and relationships with colleagues were categorised as good, whilst the job scored poorly in creativity, job security and income. The German data is presented for comparison, showing scores which are generally lower. The differences are greatest for the dimensions income, training and promotion, which are particular strengths of the UK company. However, there are no significant differences for dimensions such as whether work is meaningful or not, information, pressure and creativity which relate more to the intrinsic nature of bus driving as a job.

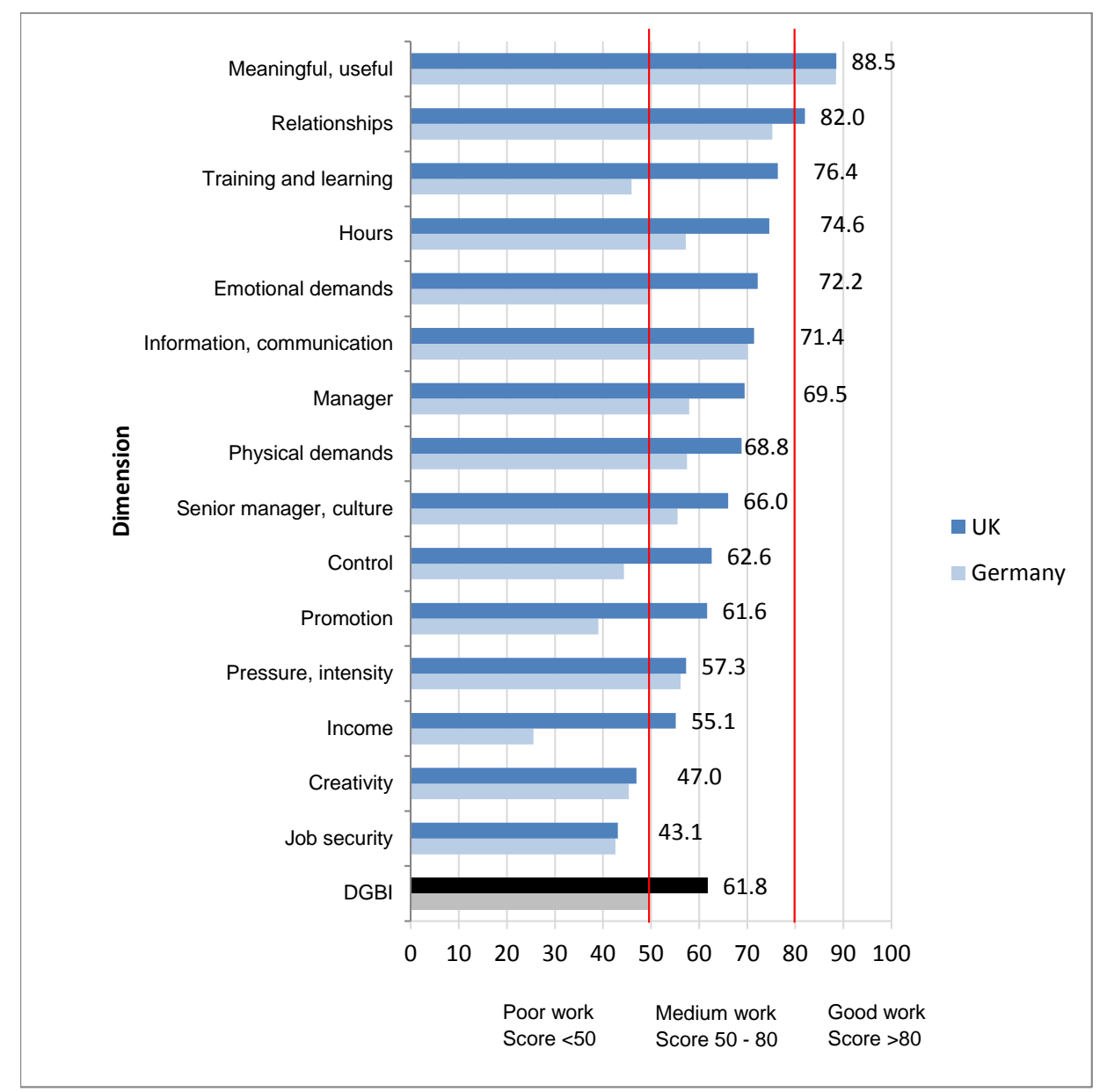

Figure 2 DGB-Index scores overall and by dimension for bus driver respondents from the UK and Germany (exact scores are shown for UK data only) 
Results were further analysed by considering the answers respondents had given to single item questions about overall job quality and health. In each case responses were dichotomised, and comparisons of DGB-Index scores were made between the two groups. A two tailed independent $t$ test was used as detailed by Brace et al (2009), as the data met the assumptions for a parametric test. As Table 5 shows, individuals who answered positively to the question 'Do you consider your job to be a good job' had significantly higher DGB-Index scores than those who answered negatively. Scores were also higher for those respondents who considered their job to be good for their health, those who considered their current health to be good, and those who felt their health would enable them to continue working in this job until they reached the age of 65 .

Table 5. DGB-Index scores for UK bus drivers, showing variation with answers to questions about overall health and job quality. (Means compared using a two tailed independent samples $t$ test)

\begin{tabular}{|c|c|c|c|c|c|}
\hline Questions & Responses & $\mathrm{n}$ & $\begin{array}{l}\text { Mean } \\
\text { DGB- } \\
\text { Index } \\
\text { score }\end{array}$ & $\mathrm{SD}$ & Significance \\
\hline \multirow[t]{2}{*}{$\begin{array}{l}\text { Do you consider your job to be a good } \\
\text { job? }\end{array}$} & Yes (definitely, mostly) & 335 & 63.2 & 15.44 & \multirow[t]{2}{*}{$*$} \\
\hline & $\begin{array}{l}\text { No (not sure, not really, } \\
\text { definitely not) }\end{array}$ & 46 & 51.0 & 16.00 & \\
\hline \multirow[t]{2}{*}{$\begin{array}{l}\text { Do you consider your job to be generally } \\
\text { good for your health? }\end{array}$} & Yes (definitely, mostly) & 92 & 69.9 & 14.62 & \multirow[t]{2}{*}{$*$} \\
\hline & $\begin{array}{l}\text { No (not sure, not really, } \\
\text { definitely not) }\end{array}$ & 282 & 59.2 & 15.50 & \\
\hline \multirow[t]{2}{*}{ How is your health, in general? } & Good (very good, good) & 280 & 64.6 & 15.59 & \multirow[t]{2}{*}{$*$} \\
\hline & $\begin{array}{l}\text { Not good (fair, bad, very } \\
\text { bad) }\end{array}$ & 101 & 53.9 & 14.45 & \\
\hline \multirow{2}{*}{$\begin{array}{l}\text { Thinking about your health and the job } \\
\text { you do at the moment, will you still be } \\
\text { able to manage it when you are } 65 ?\end{array}$} & Probably & 253 & 64.3 & 15.50 & \multirow[t]{2}{*}{$*$} \\
\hline & Probably not & 53 & 52.3 & 14.70 & \\
\hline
\end{tabular}

${ }^{*} p<0.001$ 
Finally, the data were used to identify those features which drivers considered to be unimportant. Given the two part question structure, respondents could identify features which were specifically lacking 'to a great extent' in their job, but may also state that this bothered them 'not at all'. Table 6 shows those questions where more than $10 \%$ of respondents identified that a particular feature was absent (or a negative feature present to a great extent) but this did not bother them.

Table 6. Number of respondents who indicated that a particular work factor was absent, but that this did not bother them at all

\begin{tabular}{|l|r|}
\hline & $\begin{array}{l}\text { Number of } \\
\text { respondents }\end{array}$ \\
\hline Do you have opportunities to use your own ideas at work? & $112(26 \%)$ \\
\hline Can you influence how your work time is organised? & $86(20 \%)$ \\
\hline Can you independently plan and organise your work? & $78(18 \%)$ \\
\hline Can you influence the amount of work you are asked to do? & $51(12 \%)$ \\
\hline Does your supervisor/line manager make you feel valued? & $46(11 \%)$ \\
\hline
\end{tabular}

\section{Discussion}

The aim of the current study was to assess whether the DGB-Index could be used to assess job quality in a UK bus company and it appears to have achieved this. Questionnaires were completed by a large cohort of bus drivers, and produced coherent and logical results. Job quality for bus drivers was lower than for nondrivers from the same company with the biggest differences for the dimensions creativity, control, and income and with drivers having good scores for meaningful work, relationships and training and learning.

The difference between the drivers and non-drivers illustrates that the DGB-Index can differentiate between jobs of different quality in the UK. A relatively low score for drivers would be expected in view of the literature which has found bus driving to be 
a job with unfavourable working conditions (Jettinghoff and Houtman, 2009), which provides low job satisfaction (Rose, 2003) and is bad for health (e.g.Tse et al., 2006).

The actual score for the bus drivers surveyed was 61.8 , which identifies it as 'medium quality work' according to the DGB-Index criteria (Mussman 2009). In light of the published literature about bus driving, this score is higher than may have been expected. It is also higher than the score for bus drivers from Germany, whose overall score was 49.3, indicating poor quality work. However, the UK bus company involved in the study is recognised as being a particularly good employer for the sector, with terms and conditions exceeding those of its competitors and excellent training and promotion opportunities. It is therefore plausible that its employees have higher job quality than other bus drivers in the UK. However, the lack of a comparator UK bus company is a limitation of the current study.

The German sample, by comparison, is drawn from the population at large, and does not represent any particular bus company. The German bus industry has seen significant changes over the last two decades, with improvements in passenger service being achieved through cutting driver salaries and benefits and increasing working hours (Buehler and Pucher, 2011).

Overall then, the findings in the current study are in accordance with what would be expected from the current literature and from prior knowledge of the organisation involved. However, for the DGB-Index to be considered as an effective and valid measure of job quality it needs to be able to distinguish between industries, jobs and 
employment situations in terms of their impact on health. It also needs to reflect job quality as it is perceived by individuals: the features which individuals consider important to make a job good, and those which contribute to a job being good for health are not necessarily the same (Jones et al., 2012).

\section{The DGB-Index and health}

The current study assessed self - rated health $(\mathrm{SRH})$, which has been shown to predict sickness absence, ill health and mortality (Lindberg et al., 2009; SinghManoux et al., 2007). DGB-Index scores were higher amongst those who reported that their health was good than those who considered their health to be fair or poor (Table 5) and amongst those who believed that their work was good for their health. However, it is not possible to draw conclusions about the direction of the work-health relationship. Those who have good health may view their work more positively than those who are unwell. Those with poor health may attribute this to their work, a common tendency even where problems are just as likely to relate to non-work activities (Burton et al., 2009).

The current study therefore can only tentatively confirm an association between job quality as measured by the DGB-Index and employee health. Longitudinal studies which assess job quality and health across a number of industries would be necessary to further validate the tool in this respect.

\section{The DGB-Index and individual preferences}

The association between DGB-Index scores and the question 'Do you consider your job to be a good job?' (Table 3) indicates that the factors measured by the index are 
closely associated with the factors that employees use when assessing job quality. Exactly which measures employees use in making this judgement is a matter of much debate in the literature. Rose (2007) has suggested that extrinsic factors such as pay and security are the most critical, but in fact there is wide variation between individuals regarding what they value most, with job content (Clark, 2005), relationships (Lowe and Schellenberg, 2001) and usefulness to society (Muñoz de Bustillo Llorente et al, 2009) mentioned in the literature. Preferences vary with gender (Clark, 2005), age (Kalleberg and Vaisey, 2005) and nationality (Muñoz de Bustillo Llorente, et al, 2009) as well as with personality. To create a single measurement tool which takes into account personality aspects and personal preferences as well as the many other possible facets and features, (Warr, 2007; Wadsworth et al., 2010) is therefore a challenging undertaking.

The DGB-Index, as a result of its two part question structure, accommodates this individual variation better than most, if not all, existing measures of job quality. What it measures explicitly is whether a particular job is good for the individuals doing that job at that time - which may be different from whether it measures up to a theoretical model of a job quality.

An example of this comes from the data on the dimension control over work. There is much in the literature about the adverse impact of low autonomy on health (e.g. Stansfeld and Candy, 2006; Kivimäki et al., 2012) and low levels of control are a common feature of work in transport (Jettinghoff and Houtman, 2009). However, $20 \%$ of respondents in the current study stated that although they had no opportunities to plan and organise their work and work time this did not bother them 
at all. It is possible that bus driving as a trade attracts those who have a low desire for autonomy and are more comfortable with clear structure and minimal latitude. For such people, giving them greater opportunities for decision making could potentially be uncomfortable and disadvantageous for them.

Similarly, there are some interesting contradictions in the findings regarding working hours. This has been recognised as a challenge in the industry (Escoto et al., 2010; Johansson et al., 2012; Machin and Hoare, 2008), yet within the current study hours was one of the highest scoring dimensions, with a score of 74.6. There are a number of explanations for this apparent anomaly, including the possibility that the questions about hours which are included in the DGB-Index relate to issues around their planning rather than the reality of working irregular and unsociable hours (Prümper and Richenhagen, 2009). However, it may also reflect that bus drivers are predominantly a self-selecting cohort who are comfortable with the typically long working hours and poor work life balance of their role: those who are unable to adapt leave and find alternate jobs. This is not a reason to avoid optimisation of working hours to minimise adverse health effects: but it highlights the importance of individual variation.

\section{Usefulness of the DGB-Index for employers}

The focus on job-employee match makes the DGB-Index tool particularly useful for employers, as it offers an opportunity to improve overall job quality by matching employees and jobs more effectively. This may be particularly helpful if the nature of the job itself is difficult to change. For example, in an organisation which had little scope for individuals to advance, an employee who had no interest in promotion 
would score more highly on a question about this (i.e. would consider it a relatively better job) than a colleague who had aspirations. The company in the current study use personality and aptitude testing in employee selection, and are likely to have a relatively good job-employee match: this may be a further factor contributing to the relatively high DGB-Index score. Psychometric testing has been used with bus drivers, where testing has been introduced to guide recruitment and training to minimise the incidence of accidents (Dorn et al., 2010). The DGB-Index illustrates that it may also contribute to improvements in the perceived quality of working life.

\section{Disadvantages and limitations of the DGB-Index}

The number of questions included in the DGB-Index about physical hazards is relatively low compared to those for psychosocial hazards (Prümper and Richenhagen, 2009) and this may reduce content validity. In addition, the tool asks whether there are physical demands, and scores their presence as a detrimental element. Yet there is a growing recognition that physical work can be a positive factor, with the best health outcomes from work which is moderate in its physical demands (Parkes et al, 2005; Straker and Mathiassen, 2009). The tool includes a question about strain and prolonged standing or sitting, but this is insufficient to highlight the truly sedentary nature of the work which is an important risk in bus driving as well as in many office based jobs (Boyce et al., 2008; Saris et al., 2003), and contributes significantly to increased mortality (Wilmot et al., 2012). Therefore, there would be a benefit in further developing the questions which relate to known physical health hazards. In addition, the tool does not currently address fairness and organisational justice, which have been identified as important aspects of job quality 
(Coats and Lekhi, 2008; Bonde, 2008): in this area too it would benefit from further development.

A final aspect to consider with regard to the DGB-Index is its practicality as a tool for measuring job quality across a wide range of industries. As a general principle, written questionnaires are of limited value when respondents may have restricted language or literacy skills (Bryman, 2004). Although this does not prohibit their use in job quality assessment, it does require that questions are structured as simply and clearly as possible.

Unfortunately, the structure of the DGB-Index is complex as a consequence of the two part question structure which in other respects is the main strength of the tool. This resulted in $74 \%$ of respondents in the pilot study failing to complete the questionnaire correctly. In the main study the failure rate was reduced substantially by revising the layout, adding clearer written instructions (Figure 1), giving verbal instructions (by means of a film clip of the researcher, shown to all participants), allocating work time to complete the questionnaire, and having trainers on hand to assist those who were having difficulty. However, given the resources put into maximising the responses in this study the failure rate, at $7.7 \%$, is still high. Tse et al. (2007), who used a simpler question structure with a similar cohort of bus drivers, discounted only $2 \%$ of returned questionnaires due to non-completion.

One potential improvement would be electronic administration of the questionnaire which would enable the questions to be presented in a less complex format. Although this is more difficult with employees who have limited computer access or 
poor literacy, it is achievable for a well-motivated employer (Broughton et al., 2009), and automated systems e.g. Audio Computer-Assisted Self-interviewing (Axinn and Pearce, 2006) may facilitate this. An alternate solution would be to administer the questionnaire as part of an interview, either face to face or by telephone. This could be successful if data were gathered at a population level perhaps as part of existing data collection exercises such as the EWCS or the British Household Panel Survey. However, collecting data in this way at an organisational level is unlikely to be practical: thus, in its current form, the tool is limited to use with populations which have a good level of motivation and literacy.

A strength of this study is the sample size and response rate. Incorporating the questionnaire into mandatory training provided a large, representative sample with a high initial response rate (100\%). This compares to typical response rates of $20 \%$ $50 \%$ in similar studies (Tse et al., 2007). A limitation is that the data were drawn from only one organisation; further work is in progress to gather data from two additional bus companies.

There are some limitations due to the difficulties some employees had completing the questionnaire correctly, this is likely to particularly reduce the inclusion of responses from employees who had poor literacy or language skills. One consequence of this was a moderately high level of missing data. Protocols constructed to accommodate this were slightly different from those which have been used by the German team which designed the tool: scores quoted for the current study would be approximately $2 \%$ higher if the German methodology were used. This does not significantly alter the conclusions of this paper, but would need to be 
addressed if the tool were to be more widely used for national and international comparisons.

\section{Conclusions and further work}

We have illustrated that the DGB-Index has utility outside of Germany for assessing job quality. It has good overall scale reliability, and reasonable validity as shown by the associations with the subjective single item measures of job quality and the outcome measures on health. The tool also highlights the importance of variation between individuals in their perceptions of job quality; this aspect would make it particularly useful for international comparisons, and in the exploration of cultural differences in job quality and its effect on health.

Since the DGB-Index was used to gather data for the current study, small changes have been made to the construction of the tool by its owners, in response to a review by Schütte (2011). This addresses concerns raised by Prümper and Richenhagen (2009) regarding the way the different aspects of the tool are weighted to produce the final index. The revised tool also includes a number of additional questions (Personal communication from Mussman, 2012) which may address the issue of limited assessment of physical hazards in the tool.

Further testing is required to demonstrate that the DGB-Index can usefully differentiate for specific industries between providers of jobs and between countries as this will enable learning from exemplars of best practice. Longitudinal studies are needed to confirm the validity of the tool in relation to the associations with health. 
The consent of the DGB to the use of the tool is gratefully acknowledged, and particularly the valuable assistance and support provided by Dr Frank Mussman.

\section{References}

Axinn, W.G., Pearce, L.D., 2006. Mixed Method Data Collection Strategies. New York ; Cambridge : Cambridge University Press, New York ; Cambridge.

Biggs, H., Dingsdag, D., Stenson, N., 2009. Fatigue factors affecting metropolitan bus drivers: A qualitative investigation. Work 32, 5-10.

Bonde, J.P., 2008. Psychosocial factors at work and risk of depression: a systematic review of the epidemiological evidence. Occup. Environ. Med. 65, 438-445.

Boyce, R.W., Boone, E.L., Cioci, B.W., Lee, A.H., 2008. Physical activity, weight gain and occupational health among call centre employees. Occup. Med. (Lond) 58, 238-244.

Brace, N., Kemp, R., Snelgar, R., 2009. SPSS for Psychologists. Palgrave Macmillan, Basingstoke.

Broughton, A., Tyers, C., Denvir, A., Wilson, S., O’Regan, S., 2009. Managing stress and sickness absence Progress of the Sector Implementation Plan - Phase 2. RR694.

Bryman, A., 2004. Social Research Methods. Oxford University Press, Oxford.

Buehler, R., Pucher, J., 2011. Making public transport financially sustainable. Transp. Policy 18, 126-138.

Burton, A.K., Kendall, N.A.S., Pearce, B.G., Birrell, L.N., Bainbridge, L.C., 2009. Management of work-relevant upper limb disorders: a review. Occupational Medicine 59, 44-52.

Chung, Y., Wong, J., 2011. Developing effective professional bus driver health programs: An investigation of self-rated health. Accident Analysis \& Prevention 43, 2093-2103.

Clark, A.E., 2005. Your Money or Your Life: Changing Job Quality in OECD Countries. Br. J. Ind. Relat. 43, 377-400.

Coats, D., Lekhi, R., 2008. Good Work: Job Quality in a changing economy. The Work Foundation. 
Cooke, G.B., Donaghey, J., Zeytinoglu, I.U., 2013. The nuanced nature of work quality: Evidence from rural Newfoundland and Ireland. Human Relations 66, 503-527.

Dorn, L., Stephen, L., Af Wåhlberg, A., Gandolfi, J., 2010. Development and validation of a self-report measure of bus driver behaviour. Ergonomics 53, 1420-1433.

Escoto, K.H., French, S.A., Harnack, L.J., Toomey, T.L., Hannan, P.J., Mitchell, N.R., 2010. Work hours, weight status, and weight-related behaviors: A study of metro transit workers. International Journal of Behavioral Nutrition and Physical Activity 7, art.no. 91.

French, S.A., Harnack, L.J., Hannan, P.J., Mitchell, N.R., Gerlach, A.F., Toomey, T.L., 2010. Worksite environment intervention to prevent obesity among metropolitan transit workers. Prev. Med. 50, 180-185.

Fuchs, T., 2010. Potentiale des DGB-Index Gute Arbeit für die betriebliche Anwendung und arbeitswissenschaftliche Forschung - Replik auf den Artikel von G. Richenhagen und J. Prümper in der ZfA 2/2009. Zeitschrift für Arbeitswissenschaft 64, 3-15.

Glasø, L., Bele, E., Nielsen, M.B., Einarsen, S., 2011. Bus drivers' exposure to bullying at work: An occupation-specific approach. Scand. J. Psychol. 52, 484-493.

Hendrick, H.W., 2008. Applying ergonomics to systems: Some documented "lessons learned". Appl. Ergon. 39, 418-426.

Jettinghoff, K., Houtman, I., 2009. A sector perspective on working conditions. Eurofound.

Johansson, G., Evans, G.W., Cederström, C., Rydstedt, L.W., FullerRowell, T., Ong, A.D., 2012. The effects of urban bus driving on blood pressure and musculoskeletal problems: A quasi-experimental study. Psychosom. Med. 74, 89-92.

Jones, W., Haslam, R., Haslam, C., 2012. How do people differentiate between jobs: and how do they define a good job? Work (Reading, Mass.) 41, 818-821.

Kalleberg, A.L., Vaisey, S., 2005. Pathways to a Good Job: Perceived Work Quality among the Machinists in North America. Br. J. Ind. Relat. 43, 431-454.

Karasek, R., 1979. Job Demands, Job Decision Latitude, and Mental Strain: Implications for Job Redesign. Adm. Sci. Q. 24, 285-308.

Kivimäki, M., Nyberg, S.T., Batty, G.D., Fransson, E.I., Heikkilä, K., Alfredsson, L., Bjorner, J.B., Borritz, M., Burr, H., Casini, A., Clays, E., De Bacquer, D., Dragano, N., Ferrie, J.E., Geuskens, G.A., Goldberg, M., Hamer, M., Hooftman, W.E., Houtman, I.L., Joensuu, M., Jokela, M., Kittel, F., Knutsson, A., Koskenvuo, M., Koskinen, A., Kouvonen, A., Kumari, M., Madsen, I.E., Marmot, M.G., Nielsen, M.L., Nordin, M., Oksanen, T., Pentti, J., Rugulies, R., Salo, P., Siegrist, J., Singh-Manoux, A., Suominen, S.B., Väänänen, A., Vahtera, J., Virtanen, M., Westerholm, 
P.J., Westerlund, H., Zins, M., Steptoe, A., Theorell, T., 2012. Job strain as a risk factor for coronary heart disease: a collaborative meta-analysis of individual participant data. The Lancet 380, 1491-1497.

Lindberg, P., Josephson, M., Alfredsson, L., Vingard, E., 2009.

Comparisons between five self-administered instruments predicting sick leaves in a 4-year follow-up. Int. Arch. Occup. Environ. Health 82, 227 234.

Loughlin, C., Murray, R., 2013. Employment status congruence and job quality. Human Relations 66, 529-553.

Lowe, G.S., Schellenberg, G., 2001. What's a good job?The importance of employment relationships. CPRN Study No. W|05.

Machin, M.A., Hoare, P.N., 2008. The role of workload and driver coping styles in predicting bus drivers' need for recovery, positive and negative affect, and physical symptoms. Anxiety, Stress \& Coping 21, 359-375.

Morris, J.N., Heady, J.A., Raffle, P.A.B., Roberts, C.G., Parks, J.W., 1953. Coronary heart disease and physical activity of work. The Lancet 262, 1111-1120.

Muñoz de Bustillo Llorente, R., Fernández Macías, E., Anton, J.I., Esteve, F., 2009. Indicators of job quality in the european union. European Parliament

Muñoz de Bustillo, R., Fernández-Macías, E., Esteve, F., Antón, J., 2011. E pluribus unum? A critical survey of job quality indicators. SocioEconomic Review 9, 447-475.

Mussman, F., 2009. The German "Good-Work" Index (DGB-Index Gute Arbeit).Working conditions and Health and safety surveys in Europe: stocktaking, challenges, and persepctives. The Observatoire social eruopean (OSE) 18-19 March http://www.ose.be/conf ETUI2009/slides/DGBIndex ETUI Gute Arbeit.pdf .

Niu, S., 2010. Ergonomics and occupational safety and health: An ILO perspective. Appl. Ergon. 41, 744-753.

Okunribido, O.O., Shimbles, S.J., Magnusson, M., Pope, M., 2007. City bus driving and low back pain: A study of the exposures to posture demands, manual materials handling and whole-body vibration. Appl. Ergon. 38, 29-38.

Parent-Thirion, A., Fernández Macías, E., Hurley, J., Vermeylen, G., 2007. Fourth European Working conditions survey. 2011.

Parkes, K.R., Carnell, S., Farmer, E., 2005. Musculo-skeletal disorders, mental health and the work environment; RR316. 2011.

Prümper, J., Richenhagen, G., 2009. Der DGB-Index „Gute Arbeit" - eine arbeitswissenschaftliche Bewertung <br $/>$ (The DGB index 'Good work' an ergonomical evaluation) $<$ br $/>\ln$ GfA (Hrsg.),Arbeit, 
Beschäftigungsfähigkeit und Produktivität im 21. Jahrhundert.<br />55. Kongress der Gesellschaft für Arbeitswissenschaft (S. 341-344). 2012.

Rose, M., 2007. Why so fed up and footloose in IT? Spelling out the associations between occupation and overall job satisfaction shown by WERS 2004. Industrial Relations Journal 38, 356-384.

Rose, M., 2003. Good Deal, Bad Deal? Job Satisfaction in Occupations. Work, Employment \& Society 17, 503-530.

Salmon, P.M., Young, K.L., Regan, M.A., 2011. Distraction 'on the buses': A novel framework of ergonomics methods for identifying sources and effects of bus driver distraction. Appl. Ergon. 42, 602-610.

Saris, W.H.M., Blair, S.N., Van Baak, M.A., Eaton, S.B., Davies, P.S.W., Di Pietro, L., Fogelholm, M., Rissanen, A., Schoeller, D., Swinburn, B., Tremblay, A., Westerterp, K.R., Wyatt, H., 2003. How much physical activity is enough to prevent unhealthy weight gain? Outcome of the IASO 1st Stock Conference and consensus statement. Obesity Reviews 4, 101-114.

Schütte, M., 2011. DGB-Index - A review of statistical quality criteria. 1. edition. Dortmund: Bundesanstalt für Arbeitsschutz und Arbeitsmedizin 2011. 110 pages, PDF-Datei http://www.baua.de/en/Publications/ExpertPapers/Gd61.html?nn=717206. 2012.

Siegrist, J., 1996. Adverse health effects of high-effort/low-reward conditions. J. Occup. Health Psychol. 1, 27-41.

Singh-Manoux, A., Dugravot, A., Shipley, M.J., Ferrie, J.E., Martikainen, P., Goldberg, M., Zins, M., GAZEL Cohort, 2007. The association between self-rated health and mortality in different socioeconomic groups in the GAZEL cohort study. Int. J. Epidemiol. 36, 1222-1228.

Smith, A., Wadsworth, E., Chaplin, K., Allen, P., Mark, G., 2011. What is a good job? The relationship between work/working and improved health and wellbeing. IOSH 11.1.

Stansfeld, S., Candy, B., 2006. Psychosocial work environment and mental health - A meta-analytic review. Scand. J. Work Environ. Health $32,443-462$.

Straker, L., Mathiassen, S.E., 2009. Increased physical work loads in modern work - a necessity for better health and performance? Ergonomics 52, 1215.

Tse, J.L.M., Flin, R., Mearns, K., 2007. Facets of job effort in bus driver health: Deconstructing "effort" in the effort-reward imbalance model. J. Occup. Health Psychol. 12, 48-62.

Tse, J.L.M., Flin, R., Mearns, K., 2006. Bus driver well-being review: 50 years of research. Transportation Research Part F: Traffic Psychology and Behaviour 9, 89-114. 
Wadsworth, E.J.K., Chaplin, K.S., Allen, P.H., Smith, A.P., 2010. What is a Good Job? Current Perspectives on Work and Improved Health and Well-Being. The Open Occupational Health \& Safety Journal 2, 9-15.

Wallace, C., Pichler, F., Hayes, B.C., 2007. First European Quality of Life Survey: Quality of work and life satisfaction. Eurofound. http://www.eurofound.europa.eu/pubdocs/2006/95/en/1/ef0695en.pdf

Ward, J., Haslam, C., Haslam, R., 2008. The impact of health and safety management on organisations and their staff. HSE 08.1.

Warr, P.B., 2007. Work, Happiness, and Unhappiness.; Lawrence Erlbaum Associates, Mahwah, N.J. ; London.

Wilmot, E.G., Edwardson, C.L., Achana, F.A., Davies, M.J., Gorely, T., Gray, L.J., Khunti, K., Yates, T., Biddle, S.J., 2012. Sedentary time in adults and the association with diabetes, cardiovascular disease and death: systematic review and meta-analysis. Diabetologia 55, 2895-2905 World Health Organization, 2010. Healthy Workplaces: a model for action. 